acceptance. Intensive feeding systems have been developed with in situfeeding of OPF and PKC for cattle and goats, often with rice bran or copra cake The results from 21 case studies over the past three decades showed increased yields of 0.49-3.52 mt of fresh fruit bunches (FFB)/ $\mathrm{ha} / \mathrm{yr}$; increased income by about $30 \%$; savings in weeding costs by $47-60 \%$ equivalent to $21-62 \mathrm{RM} / \mathrm{ha} / \mathrm{yr}$; and an internal rate of return of $19 \%$ based on the actual field data The advances highlight demonstrable increased productivity of animals and meat offtakes, value addition to the palm oil crop, environmental sustainability and distinct economic impacts. Additionally, carbon sequestration is enhanced through more widespread use of grasses and tree legumes, and improved forage management practices, with resultant decreased carbon atmospheric emissions and global warming. Concerted future research and development efforts are necessary on the following:

- Measurements of animal performance and crop yields under different nutritional and management regimes

- Assessments of the effects on soil

- Improved understanding of the management of animals under tree crops

- Demonstration of beneficial animal performance

- Sustainability of the production systems

- Economic benefits, and,

- The impact of integrated systems.

The resultant impact provides important socio-economic benefits and food security for resource-poor small farmers. Increasing the adoption rate in the future is associated with promoting greater awareness of the potential of integrated systems, overcoming resistance by the crop- oriented plantation sector, and promotion of wider technology application. These issues are linked directly with defining coherent policy, institutional commitment,increased investments, private sector involvement, and a stimulus package of incentives.

\title{
Organic farming principles related to agro-ecological tropical smallholder livestock systems
}

\author{
Mette Vaarst ${ }^{1 \dagger}$, Stephen Roderick ${ }^{2}$, Eduardo Lucas Vieito Reyes ${ }^{3}$, Sylvia N. Muwanga ${ }^{4}$, \\ B. Sanyal ${ }^{5}$, Mr. Pallob ${ }^{5}$, Fernando Funes Monzote ${ }^{6}$ and Ataur Bhuiyan ${ }^{7}$ \\ ${ }^{1}$ University of Aarhus, Faculty of Agricultural Sciences, P.O.Box 50, DK - 8830 Tjele, Denmark; ${ }^{2}$ Organic Studies Centre, Duchy College, Rosewarne, Cornwall, \\ TR14 OAB, UK; ${ }^{3}$ Instituto de Investigaciones de Pastos y Forrajes, apartado Postal 2348, Ciudad Habana, Cuba; ${ }^{4}$ Faculty of Veterinary Medicine, Makerere University, \\ Department of Wildlife and Animal Resources Management, P.O.Box 7062, Kampala, Uganda; ${ }^{5}$ Loka Kalyan Parishad, 59B, Chowringhee Road, Kolkata 700020, \\ West Bengal, India; ${ }^{6}$ Estación Experimental de Pastos y Forrajes, 'Indio Hatuey', Universidad de Mananza, Central España Republicana, Perico, Mantanzas, Cuba; \\ ${ }^{7} 2^{\text {nd }}$ Floor, Central Store Building, 48, Kazi Alauddin Road, Dhaka-1000, Bangladesh
}

Organic farming is built on a set of principles, e.g. expressed by IFOAM as the principles of health, ecology, fairness and care. These principles are in various ways practiced and implemented in standards and rules for organic farming, some of which is certified, labelled and marketed at a higher price than non-organic produce, typically in countries with privileged consumers who can afford to choose to pay premium price. In other settings, following the principles do not necessarily lead to certification and premium prices, but improves farming, soil fertility and/or production on short and long term basis. This paper will examine the requirements, restrictions and opportunities for organic livestock production across diverse systems of smallholder production in the tropics. We use the term organic and agro-ecological farming, meaning farming in accordance with the organic principles.

Organic livestock is unlikely to gain widespread interest for export. In relation to the local market and local consumers, it will gain interest if it produces high quality products or meets local economic conditions for low inputs or meets local sustainability requirements. The major challenge in agro-ecological and organic livestock production systems is to think the organic principles into widely different and diverse systems under a wide range of conditions and circumstances. This requires a thorough analysis of the problems, opportunities and existing knowledge. One important area which at all times need to be balanced in organic systems is the emphasis on naturalness and at the same time human care in order to ensure that animals are allowed to perform their natural behaviour as far as possible, and at the same time will not suffer as a result of hunger, disease or insufficient living conditions. This means that consideration has to be given to the individual animal (as a sentient being). Furthermore, livestock need to play a role as an integrated element of the whole farm where they produce manure to be used as a crop fertiliser and conditioner and utilise crop residues as sources of feed. Hence, there is a need to consider the role of livestock from a whole farm perspective regardless of whether they are kept in agro-forestry systems, mountain areas, or wet areas. The emphasis should at all times be on creating a basis for sustainable farming systems as part of a sustainable agricultural sector.

\footnotetext{
† E-mail: Mette.Vaarst@agrsci.dk
} 
In this paper, three examples of existing types of livestock production from three different countries will be analysed, compared and discussed in relation to the organic principles health, ecology, fairness and care. The potential and relevant directions for future development will be discussed based on this analysis. The three cases are:

(1) the case of mixed Cuban livestock farming, typically involving pigs, cattle and poultry in an agro-forestry system or rotational grazing/ fodder bank system. In the Cuban case the transition to agro-ecological system has been necessary from the early 1990s and integrated diverse systems exist, as well as a number of remaining challenges, which need to be solved,

(2) the case of Ugandan organic smallholder farms with dairy cows and possibly also small ruminants and/or poultry. In Uganda, organic farming has been growing rapidly over the last decade, to a large extent in terms of crop, fruit and vegetable production for export in certified organic systems. Here the challenges are related to integrating livestock into these systems and live up to the organic principles within the livestock sector,

(3) West Bengal integrated fish and farming systems with poultry and small ruminants (goats/sheep). The specific area taken is the Sunderbans area, which is a vulnerable eco-system and an overpopulated area. Extensive amounts of pesticides have previously been promoted, and livestock systems tend to be unbalanced in terms of nutrition cycles and land use, and where fish have largely died out because of seeding-harvest for export. This is a case of organic/agro-ecological approach being adopted for agricultural rehabilitation.

When discussing the cases, we consider various organic approaches to breeding, use of indigenous breeds, availability of outdoor access and the potential for animals to improve agriculture in the specific regions. We shall also consider the potential conflicts in achieving the multiple objectives of organic production.

In organic livestock systems, feeding should always be species-specific and as far as possible local and home-grown. This fits well into the integrated and diverse systems, although some dilemmas exist, such as meeting the protein requirements of mono-gastric animals and the potential conflict this presents with regard to human food production and needs as well as in relation to environmental issues. Although emphasis is on animal disease prevention and health promotion, an anomaly within organic legislation is the allowance of chemicals in veterinary medicine, whereas agro-chemicals are prohibited in all areas of the crop production. We will therefore also discuss the role of vaccination, traditional medicine and alternatives to biomedical treatments and other approaches to disease management under the specific conditions of the case-study areas e.g. control of vector-borne diseases in Uganda.

\title{
Level of assessment of livestock farming systems: farm, sector, and territory
}

\author{
Javier Mata ${ }^{1}$, Luis Alberto Bermejo Asensio ${ }^{1}$ and Patrick Caron $^{2 \dagger}$ \\ ${ }^{1}$ Univ. de La Laguna, Spain; ${ }^{2}$ CIRAD, France
}

Livestock production is currently facing new challenges, among which are two major ones. The first one relates to the trade off between the need for an increasing production in relationship with an increasing income in fast growing economies and demographic patterns (9 billion people in 2050) and the call for a decreasing per capita consumption in OECD countries for health reasons. The second one is the need to consider environmental concerns when looking at livestock production patterns and stimulating innovation; this relates not only to "traditional" pollution responsibility but also to the mitigation of climate change.

This calls for renewing the criteria of assessment of production and productivity. Livestock production should not only be evaluated through the volume of marketable products, such as meat, milk, eggs, etc, but also through the impact in terms of employment, greenhouse gas emission, water quality, etc. There is indeed a need for reviewing the concept of performance and the methods of its assessment. The challenge is made difficult if one considers that such an assessment should make it possible to address trade offs between the different functions of livestock production on the one hand and between levels of organization on the other hand. A dynamic could be positive at the farm level and negative at the territory level, or inversely.

After identifying these challenges, the authors will provide a quick inventory of the classical methods to assess livestock farming systems at the farm, commodity and territory levels. They will pay more attention to recent advances and examples, in particular at the territory level, through methodological approaches to understand the regional evolution of livestock systems based on the analysis of farmers' practices. The identification and interpretation of changing situations highlight the need for an explicit analysis of local, as well as global, phenomena and for an integration of different time scales. To do so, special attention can be paid to the territorial management practices of livestock systems. Such an orientation aims at taking into account the influence of space and integrating different spatial scales that are meaningful vis-à-vis changing situations.

\footnotetext{
† E-mail: patrick.caron@cirad.fr
} 